\title{
ANALISIS FAKTOR-FAKTOR YANG MEMPENGARUHI TINGKAT PENGUNGKAPAN SHARIAH GOVERNANCE PADA BANK UMUM SYARIAH ANALISIS PADA LAPORAN TAHUNAN PERIODE 2013-20171
}

\author{
Mukhibbatul Adawiyah \\ Departemen Ekonomi Syariah-Fakultas Ekonomi dan Bisnis-Universitas Airlangga \\ Email: Mukhibbatul.adawiyah-2015@feb.ac.id \\ Noven Suprayogi \\ Departemen Ekonomi Syariah-Fakultas Ekonomi dan Bisnis-Universitas Airlangga \\ Email: Noven.Suprayogi@feb.unair.ac.id
}

\begin{abstract}
This study aims to find out the simultaneous and partial influence of Firm Age, Firm Size, Third-Party Funds Growth And Predicate of GCG Self Assesment On The Level of Shariah Governance Disclosure. This study use quantitative approach. The analysis technique used is the panel data regression. The sampling technique is purposive sampling and obtain a sample of 11 shariah commercial banks in Indonesia.

This result of this study indicated that firm age, firm size, and thirs-party funds growth variables partially have a positive and significant effect, while predicate of GCG self assesment have not significant effect. Nonetheless simultaneously Firm Age, Firm Size, thirdparty funds growth and predicate of GCG self assesment have a significant effect on the level of shariah governance disclosure on shariah commercial banks in Indonesia.
\end{abstract}

Keywords: Firm Age, Firm Size, third-party funds growth, predicate of GCG self assesment, level of shariah governance disclosure, shariah commercial banks

\section{PENDAHULUAN}

Perkembangan Perbankan Syariah

di Indonesia semakin pesat ditandai dengan banyaknya Unit Usaha Syariah yang menjadi Bank Umum Syariah. Meningkatnya jumlah Bank Umum Syariah (BUS) dapat meningkatkan efektivitas fungsi intermediasi perbankan syariah sehingga tetap terjaga seiring dengan pertumbuhan dana yang dihimpun maupun pembiayaan yang relatif tinggi, serta penyediaan akses jaringan yang meningkat dan menjangkau kebutuhan masyarakat secara luas sehingga masih memiliki fundamental yang cukup kuat untuk memanfaatkan potensi membaiknya perekonomian nasional.

Salah satu pilar penting dalam pengembangan Bank Syariah yaitu adanya shariah compliance atau disebut dengan istilah kepatuhan Syariah. Menurut Zainul Arifin (2009) Kepatuhan Syariah adalah penerapan prinsip-prinsip Syariah dan tradisinya dalam transaksi vang dalam perbankan dan bisnis lainnya. Adanya Kepatuhan Syariah dianggap penting oleh pihak-pihak yang berhubungan dengan Bank Syariah. Kepatuhan Syariah menjadi pembeda antara Bank Konvensional dan Bank Syariah. Hal tersebut menjadikan sebuah

\footnotetext{
1 Jurnal ini merupakan bagian dari skripsi yang ditulis oleh Mukhibbatul Adawiyah, NIM: 041511433032, yang diuji pada 22 Juli 2019.
} 
Adawiyah, et al/Jurnal Ekonomi Syariah Teori dan Terapan Vol. 6 No. 11 November 2019: 2347-2360;

ANALISIS FAKTOR-FAKTOR YANG MEMPENGARUHI TINGKAT PENGUNGKAPAN SHARIAH GOVERNANCE PADA BANK UMUM SYARIAH ANALISIS PADA LAPORAN TAHUNAN PERIODE 2013-2017

tantangan tersendiri bagi Bank Syariah untuk selalu berkomitmen dengan mengeluarkan inovasi-inovasi terbaru seperti menghadirkan instrumen atau produk baru dan halal berdasarkan prinsip-prinsip Syariah agar masyarakat lebih memilih Bank Syariah dibanding dengan Bank Konvensional. Selain itu kepatuhan syariah dianggap penting karena berhubungan dengan kepercayaan dan keyakinan masyarakat pada bank syariah. Dalam menerapkan kepatuhan syariah maka perlu adanya pihak yang mengawasi dan memastikan sistem operasional yang dilakukan oleh Bank Syariah telah sesuai dengan prinsip Syariah atau sudah memenuhi kepatuhan Syariah, pihak tersebut yaitu Dewan Pengawas Syariah (DPS). Dewan Pengawas Syariah dan Kepatuhan Syariah menjadi aspek penting yang tidak dapat terpisahkan. DPS juga melakukan beberapa hal seperti proses supervisi, monitoring, audit dan pemberian opini syariah terhadap kepatuhan Syariah pada perbankan syariah agar selalu berkomitmen pada prinsip-prinsip Syariah.

\section{Shariah}

Governance

diperkenalkan dalam sistem tata kelola lembaga kevangan syariah sebagai bagian dari istilah Good Corporate Governance (GCG) dalam literatur Islam. Konsep dari Shariah Governance sebenarnya tidak jauh berbeda dari konsep Good Corporate Governance pada umumnya yaitu mengawasi jalannya perusahaan sesuai dengan prinsip-prinsip Islam. Bagian yang membedakan Shariah Governance dalam Good Corporate Governance (GCG) yaitu keberadaan Dewan Pengawas Syariah sebagai bagian dari struktur organisasi Perusahaan yang berperan penting dalam segala kegiatan yang dilakukan oleh perusahaan tersebut. Shariah Governance dianggap penting karena berhubungan langsung dengan kepercayaan masyarakat terhadap perbankan syariah khususnya pada aspek Kepatuhan Syariah. Pengabaian dari sistem Shariah Governance dapat menimbulkan risiko Syariah yaitu risiko yang muncul akibat ketidakpatuhan bank syariah terhadap prinsip- prinsip Syariah. (El Junusi, 2012)

\section{Pengungkapan Shariah}

Governance dianggap penting karena digunakan untuk memberikan informasi kepada masyarakat tentang seberapa lengkap dan akurat Laporan tentang Shariah Governance yang dimiliki oleh sebuah Bank Umum Syariah. Hal ini menjadi salah satu daya tarik dan menjadi nilai tambah tersendiri bagi para investor apabila sebuah Bank Umum Syariah memiliki laporan tata kelola syariah yang baik dan lengkap. Laporan tahunan dianggap sebagai sumber informasi penting bagi perusahaan. Tingkat pengungkapan Shariah Governance menggunakan sistem skoring dimana indikator pengungkapan shariah Governance disusun oleh Dzulkifli Hasan (2012). Indikator tersebut mencakup 
Adawiyah, et al/Jurnal Ekonomi Syariah Teori dan Terapan Vol. 6 No. 11 November 2019: 2347-2360; ANALISIS FAKTOR-FAKTOR YANG MEMPENGARUHI TINGKAT PENGUNGKAPAN SHARIAH GOVERNANCE PADA BANK UMUM SYARIAH ANALISIS PADA LAPORAN TAHUNAN PERIODE 2013-2017

tentang jumlah Undang-Undang yang mengatur tentang adanya Shariah Governance, Jumlah Dewan pengawas Syariah, Struktur Organisasi Perusahaan, produk dan layanan dan indikator lainnya.

Bank umum syariah harus transparan dalam melakukan kegiatan bisnisnya supaya tidak ada yang disembunyikan, sehingga menyebabkan investor kurang mempercayai terhadap Bank Umum Syariah tersebut. Transparansi terhadap segala hal sangat penting bagi bank umum syariah karena Allah SWT secara khusus menyampaikan dalam QS Al-Baqarah ayat 283 tentang larangan penyembunyian bukti, yang berbunyi :

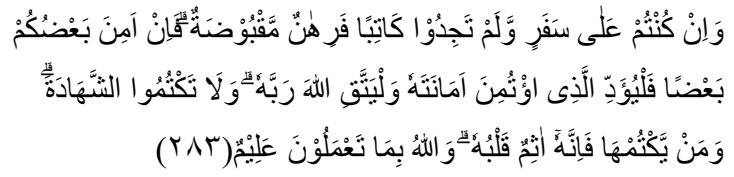
wa ing kuntum 'alā safariw wa lam tajidụ kātiban fa rihānum maqbụdah, fa in amina ba'ḍkum ba'ḍan falyu`addillażi tumina amānatahụ walyattaqillāha rabbah, wa lā taktumusysyahādah, wa may yaktum-hā fa innahū āsimung qalbuh, wallāhu bimā ta'malụna 'alim (283)

Artinya : "Jika kamu dalam perjalanan (dan bermu'amalah tidak secara tunai) sedang kamu tidak memperoleh seorang penulis, maka hendaklah ada barang tanggungan yang dipegang (oleh yang berpiutang). Akan tetapi jika sebagian kamu mempercayai sebagian yang lain, maka hendaklah yang dipercayai itu menunaikan amanatnya (hutangnya) dan hendaklah ia bertakwa kepada Allah
Tuhannya; dan janganlah kamu (para saksi) menyembunyikan persaksian. Dan barangsiapa yang menyembunyikannya, maka sesungguhnya ia adalah orang yang berdosa hatinya; dan Allah Maha Mengetahui apa yang kamu kerjakan". (QS. Al Baqarah :283)

AL-Qur'an surat Al-Baqarah ayat 283 memerintahkan seluruh transaksi dalam hal apapun untuk terbuka dan transparan, begitu juga ketika Bank Syariah mengeluarkan Laporan Tahunan yang selalu diterbitkan secara berkala guna untuk mentransparansikan segala hal yang berhubungan dengan segala transaksi pada Bank Syariah untuk kepentingan investor maupun pemangku kepentingan yang lainnya. Allah SWT pun melarang adanya penyembunyian bukti.

Teori dan penelitian terdahulu tentang Tingkat Pengungkapan Shariah Governance masih jarang ditemukan, maka dari itu penulis mengadopsi dari beberapa penelitian yang memiliki kesinambungan dengan tingkat pengungkapan Shariah Governance seperti pengungkapan tentang Good Corporate Governance (GCG) dan Corporate Social Responsibility (CSR). Fitriana (2013) mengungkapkan bahwa ukuran perusahaan berpengaruh signifikan terhadap pengungkapan Shariah Governance. Hikmah,dkk (2011) juga mengungkapkan bahwa ukuran perusahaan memberikan pengaruh yang signifikan terhadap corporate governance. Sari (2018) mengungkapkan 
Adawiyah, et al/Jurnal Ekonomi Syariah Teori dan Terapan Vol. 6 No. 11 November 2019: 2347-2360;

ANALISIS FAKTOR-FAKTOR YANG MEMPENGARUHI TINGKAT PENGUNGKAPAN SHARIAH GOVERNANCE PADA BANK UMUM SYARIAH ANALISIS PADA LAPORAN TAHUNAN PERIODE 2013-2017

bahwa Umur perusahaan memiliki pengaruh yang signifikan terhadap Tingkat Pengungkapan Islamic Social Reporting.Pertumbuhan Dana Pihak Ketiga (DPK) memiliki konsep teori yang sama dengan Investment Account Holder pada penelitian yang dilakukan oleh Farook (2011). Hasil penelitian tersebut menunjukkan adanya pengaruh positif signifikan terhadap pengungkapan Islamic Social Reporting. Hal ini membuktikan bahwa adanya pengaruh dari Pertumbuhan DPK terhadap tingkat pengungkapan shariah governance. Selain itu variabel predikat Self assesment GCG masih jarang digunakan pada penelitian-penelitian terdahulu. Self assesment GCG menilai seberapa besar perusahaan menyampaikan informasi. Apabila sebuah perusahaan memiliki hasil self assesment GCG dengan predikat baik maka perusahaan tersebut dalam menyampaikan informasi yang terdapat pada Laporan Tahunan cukup lengkap dan dapat dipercaya oleh investor dan pihak yang berkepentingan.

$$
\text { Penelitian ini bertujuan menguji }
$$

dan membuktikan pengaruh secara parsial maupun simultan umur perusahaan, ukuran perusahaan, pertumbuhan Dana Pihak Ketiga (DPK) dan predikat self assesment GCG terhadap tingkat pengungkapan Shariah Governance. Analisis dilakukan pada laporan tahunan bank umum syariah yang digunakan sebagai sampel penelitian.

\section{LANDASAN TEORI PENGEMBANGAN HIPOTESIS}

Penelitian ini didasarkan pada teori Market Discipline yang merupakan bagian dari pilar Basel II. Disiplin pasar (Market Discipline) dalam sektor perbankan dapat dimaknai sebagai situasi dimana pemegang saham, pemilik dana pihak ketiga (depositor), dan debitur besar menghadapi biaya sebagai akibat bank melakukan tindakan yang berisiko, dan mengambil tindakan pada basis biaya (Berger, 1991). Selain itu Teori Reputasi Perusahaan menyatakan bahwa semakin besar umur dan ukuran perusahaan maka tingkat pengungkapan yang dilakukan semakin besar untuk menjaga kepercayaan masyarakat dan mempertahankan reputasi perusahaan di pasar (Fobrum, 1996). Teori Supply Information (Foster, 1986) menjadi acuan dalam pertumbuhan DPK dimana semakin besar pertumbuhan dana pihak ketiga maka semakin besar kekuatan pasar yang memberikan tekanan pada perusahaan sehingga perusahaan termotivasi untuk menyampaikan informasi tentang shariah governance.

Tingkat pengungkapan shariah governance merupakan penyampaian informasi yang dilakukan oleh bank umum syariah tentang kepatuhan syariah yang dimuat dalam laporan tahunan dengan menggunakan indikator-indikator yang telah disusun oleh Dzulkifli Hasan (2012). Variabel-variabel yang mempengaruhi dari tingkat pengungkapan shariah 
Adawiyah, et al/Jurnal Ekonomi Syariah Teori dan Terapan Vol. 6 No. 11 November 2019: 2347-2360;

ANALISIS FAKTOR-FAKTOR YANG MEMPENGARUHI TINGKAT PENGUNGKAPAN SHARIAH GOVERNANCE PADA BANK UMUM SYARIAH ANALISIS PADA LAPORAN TAHUNAN PERIODE 2013-2017

governance yaitu umur perusahaan, ukuran perusahaan, pertumbuhan DPK, dan predikat self assessment GCG.

Umur perusahaan merupakan Nugroho (2009) mendefinisikan umur perusahaan merupakan awal perusahaan melakukan aktivitas operasional hingga dapat mempertahankan going concern perusahaan tersebut atau mempertahankan eksistensi dalam dunia bisnis. Menurut Widiastuti (2002) dalam Reka Yufita Sari (2018) menyatakan bahwa umur perusahaan dapat menunjukkan bahwa perusahaan tetap eksis dan mampu bersaing. Umur perusahaan berpengaruh positif terhadap tingkat pengungkapan shariah governance. Owusu-Ansah

menyatakan bahwa terdapat tiga alasan perusahaan atau bank umum syariah yang memiliki umur lebih tua akan mengungkapkan informasi yang lebih banyak dibandingkan perusahaan dengan umur yang lebih muda, antara lain:

a. Perusahaan yang lebih muda akan mengalami kerugian kompetitif apabila perusahaan mengungkapkan informasi tentang pengeluaran riset, pengeluaran modal dan pengembangan produk, kerugian tersebut muncul apabila informasi yang diungkapkan oleh perusahaan yang baru terbentuk digunakan oleh kompetitor lain. Di sisi lain, Bank Umum Syariah yang memiliki umur perusahaan yang lebih tua justru termotivasi untuk mengungkapkan informasi-informasi tersebut karena penyajian informasi tidak akan membahayakan posisi kompetitif mereka.

b. Biaya dan kemudahan dalam mengumpulkan, mengolah, dan menyebarkan informasi yang diperlukan juga dianggap sebagai kendala dalam mengungkapkan informasi sehingga Bank syariah yang memiliki umur perusahaan yang lebih muda akan kesulitan karena biaya tersebut dianggap sangat besar.

c. Bank Syariah dengan umur pemsahaan yang lebih muda belum memiliki track record yang dapat diandalkan. Pengalaman serta historis dari bank syariah tersebut dianggap kurang mencukupi sehingga kurang memiliki insentif untuk melakukan pengungkapan yang lebih banyak.

Beberapa alasan di atas juga didukung oleh beberapa penelitian dari Liu dan Anbunmozhi (2008); Hossain dan Hammami (2009); Omar dan Simon (2011) yang menyatakan bahwa umur perusahaan memiliki hubungan positif dengan tingkat pengungkapan Shariah Governance.

H1: Umur perusahan berpengaruh positif terhadap tingkat pengungkapan Shariah Governance.

Menurut Brigham dan Houston (2010:4) Ukuran perusahaan adalah ukuran besar kecilnya perusahaan yang ditunjukkan dan dinilai oleh total aset, total penjualan, beban pajak, jumlah 
Adawiyah, et al/Jurnal Ekonomi Syariah Teori dan Terapan Vol. 6 No. 11 November 2019: 2347-2360;

ANALISIS FAKTOR-FAKTOR YANG MEMPENGARUHI TINGKAT PENGUNGKAPAN SHARIAH GOVERNANCE PADA BANK UMUM SYARIAH ANALISIS PADA LAPORAN TAHUNAN PERIODE 2013-2017

laba, dll. Sharma (2014) yang menyatakan bahwa ukuran perusahaan yang besar akan mengungkapkan informasi yang banyak kepada publik untuk mengurangi biaya agensi sehingga dapat menimimalkan terjadinya asymetric information dan lebih terarah alur komunikasinya. Perusahaan yang besar adalah perusahaan yang memiliki sumber daya yang banyak dalam melakukan pengungkapan yang sesuai dengan Islam sehingga lebih dibutuhkan sumber daya manusia, pembiayaan, dan fasilitas yang lebih banyak dibandingkan perusahaan dengan ukuran yang kecil (Othman et al, 2009). Penelitian yang menemukan ukuran perusahaan berpengaruh positif terhadap tingkat pengungkapan shariah governance adalah Raditya (2012); Fitriana (2013); dan Hikmah (2011).

H2: Ukuran perusahaan berhubungan positif signifikan terhadap tingkat pengungkapan shariah governance.

Pertumbuhan DPK berasal dari penghimpunan dana dari masyarakat atau yang sering disebut dengan nasabah. Investor muslim menentukan keputusan untuk memilih bank umum syariah dengan melihat ketaatan terhadap prinsip-prinsip syariah berdasarkan pengungkapan shariah governance yang disampaikan kepada masyarakat. Apabila semakin banyak dana pihak ketiga pada bank umum syariah maka tanggungjawab bank umum syariah untuk mengungkapkan informasi tentang shariah governance juga semakin besar. Selain itu tekanan dari kekuatan pasar menjadikan perusahaan semakin termotivasi untuk melakukan pengungkapan sehingga semakin besar kekuatan pasar maka pengungkapan shariah governance juga semakin besar. H3: Pertumbuhan DPK berhubungan positif signifikan terhadap tingkat pengungkapan shariah governance.

Self assessment GCG merupakan kegiatan yang dilakukan oleh bank umum syariah sebagai penilaian pada tata kelola perusahaan yang dikelolanya. Predikat Self Assesment GCG diproksiksikan degan nilai komposit Good Corporate Governance (GCG ). Nilai komposit GCG memiliki hubungan yang positif terhadap tingkat pengungkapan shariah governance. Hal itu disebabkan karena shariah governance merupakan bagian dari Good Corporate Governance, sedangkan nilai komposit merupakan hasil dari penilaian self assesment perusahaan yang mencerminkan keadaan dari perusahaan tersebut. Apabila hasil self assesment baik maka nilai komposit yang dihasilkan juga baik sehingga pengungkapan informasi yang disampaikan oleh perusahan tersebut juga baik (Al Farizi, 2015).

H4: Predikat self assesment GCG berhubungan positif signifikan terhadap tingkat pengungkapan shariah governance.

Berdasarkan hipotesis yang telah dirumuskan, maka model analisis yang digunakan sebagai berikut: 
Adawiyah, et al/Jurnal Ekonomi Syariah Teori dan Terapan Vol. 6 No. 11 November 2019: 2347-2360; ANALISIS FAKTOR-FAKTOR YANG MEMPENGARUHI TINGKAT PENGUNGKAPAN SHARIAH GOVERNANCE PADA BANK UMUM SYARIAH ANALISIS PADA LAPORAN TAHUNAN PERIODE 2013-2017

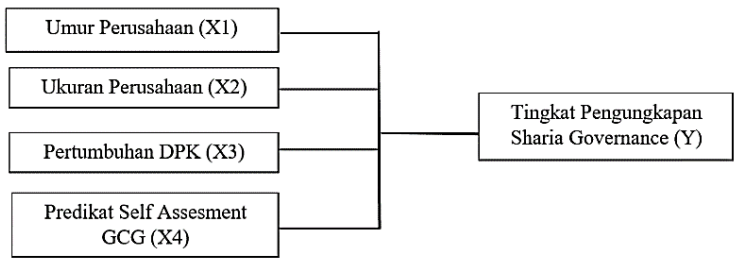

Sumber: data diolah,2018

\section{Gambar 1.}

\section{Model Analisis}

\section{METODE PENELITIAN}

\section{Pendekatan Penelitian}

Pendekatan penelitian ini adalah pendekatan kuantitatif. Menurut Sugiyono (2013) Pendekatan kuantitatif adalah metode penelitian yang berlandaskan pada filsafat positivisme, digunakan untuk meneliti pada populasi atau sampel tertentu, yang dilakukan secara sistematis dan terarah sejak awal dilakukan penelitian hingga mendapatkan hasil penelitian.

\section{Definisi Operasional Variabel}

Tingkat pengungkapan shariah governance merupakan Rasio pengungkapan Shariah Governance yang diperoleh melalui mekanisme pemberian skor atas item-item komponen pengungkapan Shariah Governance yang diungkapkan dalam laporan tahunan Bank Umum Syariah. Penelitian ini menggunakan indeks ISR yang digunakan oleh DZulkifli Hasan (2012) yang terdiri atas 30 item pengungkapan

IESGD $=\frac{\text { jumiah indikator yang diungkapkan }}{\text { jumlah maksimum Indikator }} x 100$

Keterangan:

IESGD = Indicator Extent of Shariah Governance Disclosure
Umur perusahaan merupakan lamanya perusahaan tersebut berdiri sejak didirikan dan dapat bertahan dalam arus pasar yang semakin berkembang. Umur perusahaan dapat dihitung dengan cara mengurangi tahun observasi dengan tahun berdirinya perusahaan tersebut.

Menurut Sari (2018) Cara menghitung ukuran perusahaan yaitu logarithma natural total aset (In). Data diperoleh dari Laporan Kevangan yang tercantum pada Laporan Tahunan Bank Umum Syariah pada tahun 2013-2017

Ukuran Perusahaan = In (total asset)

Pertumbuhan dana pihak ketiga (DPK) adalah prosentase dari selisih jumlah dana pihak ketiga pada tahun sekarang dengan tahun sebelumnya. Dana Pihak ketiga terdiri dari jumlah tabungan, deposito dan giro dari Bank Umum Syariah yang digunakan sebagai objek penelitian.

$$
\text { Pert. DPK }=\frac{T \mathrm{n}-\mathrm{T}(\mathrm{n}-1)}{\mathrm{T}_{(\mathrm{n}-1)}} \mathrm{X} 100 \%
$$

Keterangan:

Pert. DPK : Pertumbuhan Dana Pihak Ketiga

Tn : Jumlah Dana Pihak Ketiga pada tahun sekarang

T(n-1) : Jumlah Dana Pihak Ketiga pada tahun sebelumnya

Predikat self assesment good corporate governance (GCG) diproksikan menggunakan nilai komposit hasil self assesment pelaksaaan GCG sesuai dengan Surat edaran Bank Indonesia nomor 12/13/DPbS tahun 2010 perihal pelaksanaan GCG bagi Bank Umum Syariah dan Unit Usaha Syariah yang 
Adawiyah, et al/Jurnal Ekonomi Syariah Teori dan Terapan Vol. 6 No. 11 November 2019: 2347-2360; ANALISIS FAKTOR-FAKTOR YANG MEMPENGARUHI TINGKAT PENGUNGKAPAN SHARIAH GOVERNANCE PADA BANK UMUM SYARIAH ANALISIS PADA LAPORAN TAHUNAN PERIODE 2013-2017

dilakukan pada masing-masing bank yang tercantum dalam laporan tahunan perusahaan.

Populasi, Sampel dan Teknik Pengambilan Sampel

Populasi dalam penelitian ini adalah Bank Umum Syariah yang telah terdaftar di Bank Indonesia (BI) dan Otoritas Jasa keuangan (OJK) dan telah beroperasi pada periode tahun 2013-2017 dan memiliki laporan keuangan tahunan secara lengkap pada periode tahun 20132017 yang telah dipublikasi pada website resmi masing-masing Bank Umum Syariah. Data OJK pada tahun 2018 terdaftar 14 Bank Umum Syariah. Pengambilan sampel dalam penelitian ini menggunakan purposive sampling sehingga didapatkan 11 Bank Umum Syariah sebagai sampel penelitian.

Berikut adalah ringkasan pengambilan sampel sebagai berikut:

Tabel 1.

Ringkasan Pengambilan Sampel

\begin{tabular}{|c|c|c|}
\hline No & Nama Bank & Jumlah \\
\hline 1. & $\begin{array}{c}\text { Bank Umum Syariah } \\
\text { yang terdaftar di Bl dan } \\
\text { OJK }\end{array}$ & 14 bank \\
\hline 2. & $\begin{array}{c}\text { Bank Umum Syariah } \\
\text { yang sesuai dengan } \\
\text { sampel penelitian yang } \\
\text { dilakukan pada tahun } \\
2013-2017\end{array}$ & 11 bank \\
\hline 3. & $\begin{array}{c}\text { Bank Umum Syariah } \\
\text { yang tidak sesuai } \\
\text { dengan sampel } \\
\text { penelitian yang } \\
\text { dilakukan pada tahun } \\
2013-2017\end{array}$ & 3 bank \\
\hline 4. & $\begin{array}{c}\text { Laporan keuangan } \\
\text { yang dilakukan pada } \\
\text { penelitian tahun 2013- } \\
2017\end{array}$ & 5 bank \\
\hline 5. & Jumlah data pada & 55 data \\
\hline
\end{tabular}

\begin{tabular}{|c|c|c|}
\hline & $\begin{array}{c}\text { penelitian yang akan } \\
\text { dilakukan }\end{array}$ & \\
\hline
\end{tabular}

Sumber: data diolah, 2019

\section{Teknik Analisis}

Teknik analisis yang digunakan dalam penelitian ini yaitu model regresi linier data panel. Regresi data panel merupakan teknik analisis regresi yang menggabungkan data time series dengan data cross section. Menurut Widarjono (2013) metode regresi linier data panel mempunyai beberapa keuntungan, yaitu

1. Data panel yang merupakan gabungan dari data time series dan cross section lebih banyak menyediakan data sehingga akan menghasilkan degree of freedom yang lebih besar.

2. Menggabungkan informasi dari data time series dan scross section dapat mengatasi masalah yang timbul ketika ada masalah penghilangan variabel (ommited-variabel).

\section{HASIL DAN PEMBAHASAN}

\section{Uji Statistik Deskriptif}

Hasil analisis statistik deskriptif dapat dilihat pada tabel di bawah ini:

Tabel 2.

Hasil Uji Statistik Deskriptif

\begin{tabular}{|c|c|c|c|c|c|}
\hline & $\mathrm{N}$ & $\begin{array}{c}\text { Mea } \\
\mathrm{n}\end{array}$ & Max & Min & $\begin{array}{l}\text { Std. } \\
\text { Dev }\end{array}$ \\
\hline $\begin{array}{c}\text { Tingk. } \\
\text { Pengk. } \\
\text { SG }\end{array}$ & $\begin{array}{l}5 \\
5\end{array}$ & 0,67 & 0,87 & 0,47 & 0,0859 \\
\hline AGE & $\begin{array}{l}5 \\
5 \\
\end{array}$ & 6 & 21 & 3 & $\begin{array}{c}4,2192 \\
95 \\
\end{array}$ \\
\hline SIZE & $\begin{array}{l}5 \\
5 \\
\end{array}$ & $\begin{array}{c}7,04 \\
4 \\
\end{array}$ & $\begin{array}{l}87,9 \\
40 \\
\end{array}$ & $\begin{array}{l}1,27 \\
5 \\
\end{array}$ & $\begin{array}{c}23916, \\
93\end{array}$ \\
\hline DPK & $\begin{array}{l}5 \\
5 \\
\end{array}$ & 0,19 & 0,78 & $\begin{array}{c}- \\
0,24\end{array}$ & 0,18 \\
\hline COMPO & 5 & 1,74 & 3,4 & 1,12 & 0,6494 \\
\hline
\end{tabular}


Adawiyah, et al/Jurnal Ekonomi Syariah Teori dan Terapan Vol. 6 No. 11 November 2019: 2347-2360; ANALISIS FAKTOR-FAKTOR YANG MEMPENGARUHI TINGKAT PENGUNGKAPAN SHARIAH GOVERNANCE PADA BANK UMUM SYARIAH ANALISIS PADA LAPORAN TAHUNAN PERIODE 2013-2017

\section{\begin{tabular}{l|l|l|l|l|l|} 
SIT & 5 & & & & 24 \\
\hline
\end{tabular}}

Berdasarkan tabel 2 hasil uji statistik deskriptif rata-rata dari umur perusahaan sebesar 6, nilai tertinggi yaitu 21. Nilai terendah yaitu 3. Standar deviasi dari umu perusahaan yaitu 4,219295. Sedangkan rata-rata dari ukuran perusahaan sebesar Rp. 7,044.00, nilai tertinggi yaitu Rp 87,940.00. Nilai terendah yaitu Rp 1,275.00. Standar deviasi dari total asset yaitu $23916,93013$.

Selanjutnya rata-rata Pertumbuhan DPK sebesar 0,19. Nilai tertinggi sebesar 0,78 nilai terendah dari Pertumbuhan DPK yaitu sebesar 0,16. Standar deviasi Pertumbuhan DPK yang diperoleh yaitu sebesar 0,18. Untuk variabel Predikat Self Assesment GCG rata-rata yang diperoleh sebesar 1,74. Nilai tertinggi yaitu sebesar 3,4 dan nilai terendah yaitu 1,12. Standar deviasi dari predikat self assesment GCG sebesar 0,649424.

\section{Hasil Estimasi model regresi data panel}

Untuk menghasilkan metode yang terbaik maka dilakukan beberapa uji yaitu Uji Chow dan Uji Hausman. Uji Chow digunakan untuk memilih model terbaik antara Commond Effect Model (CEM) atau Fixed Effect Model (FEM) sedangkan Uji Hausman digunakan untuk memilih model terbaik antara Fixed Effect Model (FEM) atau Random Effect Model (REM).

Uji Chow

\section{Tabel 3.}

Hasil Uji Chow

\begin{tabular}{|c|c|c|c|}
\hline $\begin{array}{c}\text { Effect } \\
\text { Test }\end{array}$ & Statistic & D.f & Prob. \\
\hline $\begin{array}{c}\text { Cross- } \\
\text { section } \mathrm{F}\end{array}$ & 2,743182 & $(10,40)$ & 0,0114 \\
\hline
\end{tabular}

Sumber: Data eviews 10, 2019

Tabel 3 menunjukkan bahwa perolehan nilai probabilitas (Cross-section F) sebesar 0,0114 lebih kecil dari 0,05 atau $5 \%$ sehingga HO ditolak. Dapat disimpulkan bahwa model terbaik yang digunakan antara Fixed effect Model (FEM) atau Common Effect Model (CEM) dalam penelitian ini adalah Fixed Effect Model (FEM).

Uji Hausman

Tabel 4.

Hasil Uji Hausman

\begin{tabular}{|c|c|c|c|}
\hline $\begin{array}{c}\text { Test } \\
\text { Summary }\end{array}$ & $\begin{array}{c}\text { Chi-Sq. } \\
\text { Statistic }\end{array}$ & $\begin{array}{c}\text { Chi- } \\
\text { Sq. } \\
\text { D.f }\end{array}$ & Prob. \\
\hline $\begin{array}{c}\text { Cross- } \\
\text { section } \\
\text { random }\end{array}$ & 8,559127 & 4 & 0,0731 \\
\hline
\end{tabular}

Sumber: data eviews 10, 2019

Tabel 4 menunjukkan bahwa perolehan nilai probabilitas (Cross-section random) sebesar 0,0731 lebih besar dari 0,05 atau $5 \%$ sehingga $\mathrm{HO}$ diterima. Dapat disimpulkan bahwa model terbaik yang digunakan antara Fixed effect Model (FEM) atau Random Effect Model (REM) dalam penelitian ini adalah Random Effect Model (REM).

\section{Uji Asumsi klasik}

\section{Uji Normalitas}

Uji Normalitas bertujuan untuk menguji sampel yang digunakan terdistribustri normal atau tidak. Model Regresi yang baik yang baik adalah model regresi yang memiliki sampel terdistribusi normal atau mendekati normal, sehingga layak dilakukan pengujian secara statistik (Ghozali,201 1:160). 
Adawiyah, et al/Jurnal Ekonomi Syariah Teori dan Terapan Vol. 6 No. 11 November 2019: 2347-2360; ANALISIS FAKTOR-FAKTOR YANG MEMPENGARUHI TINGKAT PENGUNGKAPAN SHARIAH GOVERNANCE PADA BANK UMUM SYARIAH ANALISIS PADA LAPORAN TAHUNAN PERIODE 2013-2017

Tabel 5.

Hasil Analisis uji normalitas

\begin{tabular}{|l|l|}
\hline Jarque-Bera & 1,001910 \\
\hline Probability & 0,605952 \\
\hline
\end{tabular}

Sumber : Data eviews 10, 2019

Berdasarkan tabel 5 hasil analisis uji normalitas menggunakan Jarque Bera menunjukkan nilai 1,001910 sedangkan nilai probabilitas sebesar 0,605952 dimana nilai tersebut lebih besar dari 0,05 atau 5\%. Apabila probabilitas > 0,05 (tidak signifikan) maka data yang digunakan terdistribusi normal.

\section{Uji Multikolinearitas}

Menurut Ghozali (2011:105-106) Uji multikolinearitas digunakan untuk menguji apakah terdapat korelasi antar variabel independen dalam model regresi. Jika terjadi korelasi maka dinamakan problem multikolinearita

Tabel 6.

Hasil uji multikolinearitas

\begin{tabular}{|l|l|l|l|l|}
\hline \multicolumn{5}{|c|}{ Correlations } \\
\hline & AGE & SIZE & DPK & COMP \\
\hline AGE & 1,000 & 0,708 & $-0,324$ & 0,37012 \\
\hline SIZE & 0,708 & 1,000 & $-0,144$ & 0,32742 \\
\hline DPK & 0,370 & 0,327 & 1,000 & $-0,2511$ \\
\hline $\begin{array}{l}\text { COM } \\
\text { P }\end{array}$ & $-0,324$ & 0,144 & $-0,251$ & 1,000 \\
\hline
\end{tabular}

Sumber:e-views 10, 2019

Tabel 6 menunjukkan bahwa nilai correlations dari variabel umur perusahaan (AGE), ukuran perusahaan (SIZE), pertumbuhan DPK (DPK), dan predikat self assessment GCG (COMPOSIT) menunjukkan nilai kurang dari 0,8. Dapat disimpulkan bahwa tidak terdapat korelasi antar variabel.

\section{Uji Heteroskedastisitas}

Menurut Ghozali (2011:139) uji heterokedastisitas bertujuan untuk menguji apakah dalam model regresi terjadi ketidaksamaan varians dalam satu pengamatan lainnya. Pada penelitian ini, hasil estimasi yang diperoleh yaitu menggunakan Random Effect Model (REM), maka tidak diperlukan adanya uji heterokedastisitas dikarenakan metode Random Effect Model (REM)yang menggunakan metode generalized Least Square (GLS) dapat mengabaikan persoalan pelanggaran asumsi klasik (heteroskedastisitas,

autokorelasi) sehingga pengujian asumsi klasik dianggap selesai (Sedyadi, 2014).

\section{Koefisien Determinasi $\left(\mathbf{R}^{2}\right)$}

Koofisien Determinasi $\mathrm{R}^{2}$ dilakukan untuk melihat seberapa jauh kemampuan variabel eksogen dalam menjelaskan variabel endogen.

Tabel 7.

Hasil Koofisien Determinasi $\mathbf{R}^{2}$

\begin{tabular}{|c|c|}
\hline R-squared & 0,545100 \\
\hline Adjusted R-Squared & 0,508708 \\
\hline
\end{tabular}

Sumber : Data diolah. 2018

Berdasarkan tabel 7 di atas nilai Rsquared sebesar 0,545100 atau 54,5\%. Dapat disimpulkan bahwa variabel umur perusahaan, ukuran perusahaan, pertumbuhan DPK, dan Predikat Self Assesment GCG dapat berpengaruh sebesar 54,5\% terhadap variabel tingkat pengungkapan shariah governance.

\section{Uji F Statistic}

Uji statistik $F$ dilakukan untuk mengetahui apakah semua variabel independen yang dimasukkan dalam model regresi memberikan pengaruh signifikan secara simultan/bersama-sama 
Adawiyah, et al/Jurnal Ekonomi Syariah Teori dan Terapan Vol. 6 No. 11 November 2019: 2347-2360; ANALISIS FAKTOR-FAKTOR YANG MEMPENGARUHI TINGKAT PENGUNGKAPAN SHARIAH GOVERNANCE PADA BANK UMUM SYARIAH ANALISIS PADA LAPORAN TAHUNAN PERIODE 2013-2017

terhadap variabel dependen (Ghozali 2011 :98). Berikut adalah hasil uji F Statistik:

Tabel 8.

Hasil Uji F Statistik

\begin{tabular}{|c|c|}
\hline F-statistic & 14,97858 \\
\hline Prob (F-Statistic) & 0,00000 \\
\hline
\end{tabular}

Sumber: data diolah, 2019

Berdasarkan tabel 8 Hasil uji $\mathrm{F}$ statistik yang ditunjukkan pada tabel 4. merupakan hasil uji $\mathrm{F}$ pada model terbaik yaitu Random Effect Model (REM). Nilai dari probabilitas yang ditunjukkan pada tabel Prob(F-statistic) sebesar 0,000000 yang berarti nilainya kurang dari tingkat signifikan 0,05 atau 5\%. Apabila nilai probabilitas kurang dari 0,05 atau 5\% maka $\mathrm{HO}$ ditolak dan diterimanya $\mathrm{Hl}$. Dapat disimpulkan bahwa variabel umur perusahaan, ukuran perusahaan, pertumbuhan DPK, Predikat Self Assesment GCG secara simultan berpengaruh signifikan terhadap Tingkat Pengungkapan Shariah Governance.

Uji T Parsial

Uji T Parsial dilakukan untuk mengetahui pengaruh masing-masing variabel eksogen terhadap variabel endogen. Berikut adalah hasil dari uji T parsial

Tabel 9.

Hasil Uji † Parsial

\begin{tabular}{crrrr}
\hline \hline Variable & Coefficient & Std. Error & t-Statistic & Prob. \\
\hline \hline C & -0.173967 & 0.276823 & -0.628440 & 0.5326 \\
AGE & 0.087781 & 0.021484 & 4.085897 & 0.0002 \\
SIZE & 0.021172 & 0.010178 & 2.080179 & 0.0427 \\
DPK & 0.109254 & 0.040474 & 2.699334 & 0.0095 \\
COMPOSIT & 0.010179 & 0.012342 & 0.824727 & 0.4134 \\
\hline
\end{tabular}

Berdasarkan tabel 9 Hasil uji $\dagger$

parsial menunjukkan bahwa Umur perusahaan (AGE) berpengaruh positif signifikan terhadap tingkat pengungkapan shariah governance yang dihitung dari hasil olahan data statistik dengan nilai koofisien sebesar 0.087781 dan tingkat signifikansi sebesar 0,0002. Bank umum syariah yang memiliki umur perusahaan yang lebih tua cenderung memiliki reputasi baik. Maka dari itu, bank umum syariah yang memiliki umur lebih tua akan lebih memberikan pengungkapan informasi tentang shariah governance dibandingkan dengan bank umum syariah yang lebih muda untuk meningkatkan kepercayaan dan mempertahankan reputasi perusahaan di pasar.

Ukuran perusahaan

berpengaruh positif signifikan terhadap tingkat pengungkapan shariah governance yang dihitung dari hasil olahan data statistic 0,021172 dan tingkat signifikansi sebesar 0,0427. Bank umum syariah yang memiliki ukuran perusahaan yang besar memiliki tanggungjawab yang lebih besar untuk mengungkapkan informasi tentang shariah governance kepada pihak-pihak yang menjadi pengawas dari bank, maka semakin besar Ukuran bank umum syariah, semakin besar pengungkapan informasi yang diberikan kepada pihak-pihak pengawas.

Pertumbuhan DPK berpengaruh positif signifikan terhadap tingkat pengungkapan shariah governance yang dihitung dari hasil olahan data statistic dengan nilai koefisien sebesar 0,109254 dan tingkat signifikansi sebesar 0,0095. Semakin tinggi pertumbuhan DPK maka 
Adawiyah, et al/Jurnal Ekonomi Syariah Teori dan Terapan Vol. 6 No. 11 November 2019: 2347-2360;

ANALISIS FAKTOR-FAKTOR YANG MEMPENGARUHI TINGKAT PENGUNGKAPAN SHARIAH GOVERNANCE PADA BANK UMUM SYARIAH ANALISIS PADA LAPORAN TAHUNAN PERIODE 2013-2017

tekanan yang diterima dari kekuatan pasar akan lebih besar sehingga memberikan motivasi kepada bank umum syariah untuk memberikan informasi yang lebih banyak namun tidak lepas dari adanya kepatuhans syariah yang harus dipenuhi oleh bank umum syariah.

Predikat Self Assesment GCG tidak berpengaruh signifikan terhadap tingkat pengungkapan shariah governance yang dihitung dari hasil olahan data statistik dengan nilai koefisien sebesar 0,010179 dan tingkat signifikansi sebesar 0,4134. Tidak adanya regulasi khusus yang menetapkan kewajiban tentang pengungkapan shariah governance menjadikan bank umum syariah ada yang mengungkapkan adapula yang tidak mengungkapkan informasi tentang shariah governance sehingga predikat self assessment GCG menjadi tidak berpengaruh terhadap tingkat pengungkapan shariah governance.

Umur perusahaan, ukuran perusahaan, pertumbuhan DPK, dan predikat self assessment GCG secara simultan berpengaruh positif signifikan terhadap tingkat pengungkapan shariah governance bank umum syariah di Indonesia periode 2013-2017. Hal tersebut diketahui dari hasil olahan data statistic dengan nilai koefisien sebesar 14,90 dan nilai signfikansi sebesar 0,00000 . Nilai koefisien determinasi $\left(R^{2}\right)$ sebesar 0,543862 atau $55 \%$ menandakan bahwa variabel umur perusahaan, ukuran perusahaan, pertumbuhan DPK, dan predikat self assessment GCG dapat mempengaruhi variabel tingkat perngungkapan shariah governance sebesar $55 \%$.

\section{SIMPULAN}

Berdasarkan hasil penelitian dapat disimpulkan bahwa secara parsial variabel umur perusahaan, ukuran perusahaan, dan pertumbuhan DPK berpengaruh positif dan signifikan terhadap tingkat pengungkapan Shariah Governance pada Bank Umum Syariah di Indonesia. Sedangkan predikat self assessment GCG tidak berpengaruh terhadap tingkat pengungkapan Shariah Governance.

Sedangkan secara simultan variabel umur perusahaan, ukuran perusahaan, dan pertumbuhan DPK, dan predikat self assessment GCG berpengaruh terhadap tingkat pengungkapan Shariah Governance pada Bank Umum Syariah periode 20132017.

Berdasarkan hasil analisis dan simpulan yang telah dikemukakan di atas, maka saran yang dapat diberikan oleh penulis adalah: (1) disarankan kepada regulator atau pemerintah untuk membuat aturan atau regulasi yang fokus membahas tentang shariah governance pada perbankan syariah khususnya pada bank umum syariah. (2) Bagi penelitian selanjutnya diharapkan dapat menambah periode penelitian, memberikan variabel yang beragam pada penelitian tentang tingkat pengungkapan shariah governance, agar dapat diketahui faktor-faktor lain yang 
Adawiyah, et al/Jurnal Ekonomi Syariah Teori dan Terapan Vol. 6 No. 11 November 2019: 2347-2360; ANALISIS FAKTOR-FAKTOR YANG MEMPENGARUHI TINGKAT PENGUNGKAPAN SHARIAH GOVERNANCE PADA BANK UMUM SYARIAH ANALISIS PADA LAPORAN TAHUNAN PERIODE 2013-2017

memiliki hubungan terhadap tingkat pengungkapan shariah governance, menggunakan teknik analisis yang berbeda seperti kuisioner langsung yang diberikan kepada industry perbankan syariah agar hasil yang didapatkan lebih akurat atas pengungkapan shariah governance yang dilakukan oleh perusahaan. (3) Bagi Industri Perbankan Syariah, Pengungkapan shariah governance merupakan suatu hal yang harus dilakukan bagi Industri perbankan syariah yang disini difokuskan pada bank umum syariah, karena perbankan syariah merupakan lembaga intermediasi yang harus lebih memperhatikan segala sesuatu yang diungkapkan kepada masyarakat agar masyarakat lebih meningkatkan rasa kepercayaan untuk berinvestasi kepada bank umum syariah. Industri perbankan syariah juga harus mendorong optimalisasi pengungkapan shariah governance mengingat bahwa variabel Pertumbuhan DPK memiliki pengaruh positif signifikan terhadap pengungkapan shariah governance sehingga motivasi untuk melakukan pengungkapan shariah governance juga akan lebih meningkat.

\section{DAFTAR PUSTAKA}

N Berger, A.N. (1991). Market Discipline in banking in proceedings of a conference on Bank structure and competition. Federal Reserve Bank of Chicago.

Brigham, Eugene dan F. Houston. (2010). Dasar-Dasar Manajemen
Keuangan Buku 1 (Edisi 11). Jakarta: Salemba Empat.

Departemen Pendidikan Nasional. (2012). Kamus Besar Bahasa Indonesia. Jakarta: Balai Pustaka

Departemen Agama RI. (2011). Al-Qur'an Tajwid dan Terjemah. Bandung: CV Penerbit Diponegoro.

El Junusi, Rahman. (2012). Implementasi Syariah Governance serta implikasinya terhadap reputasi dan kepercayaan bank syariah. Al Tahrir, vol. 12, no. 1, IAIN Walisongo Semarang

Farook. S., Hassan, M.K, Lanis R. (2011). Determinant of Corporate Social Responsibility Disclosure, the case of Islamic Banks. Journal of Islamic Accounting and Bussines Research, 114-141.

Foster. G. (1986) Financial Statement Analysis. Second Edition. New Delhi: Pearson Education Inc.

Giannarakis. (2014). The Determinant Influencing of the Extent of Corporate Social Responsibility Disclosure. Internatioanl Journal Low and Management, Vol. 56, hal 393-416.

Gujarati dan Porter. (2012). Dasar-Dasar Ekonometrika. Jakarta: Salemba Empat.

Grais, Wafik dan Pallegrini, Matteo. (2006). Corporate Governance and Shariah Compliace in Institutional Offering Islamic Finance Service. 
Adawiyah, et al/Jurnal Ekonomi Syariah Teori dan Terapan Vol. 6 No. 11 November 2019: 2347-2360;

ANALISIS FAKTOR-FAKTOR YANG MEMPENGARUHI TINGKAT PENGUNGKAPAN SHARIAH GOVERNANCE

PADA BANK UMUM SYARIAH ANALISIS PADA LAPORAN TAHUNAN PERIODE 2013-2017

Policy Research Working Paper World Bank.

Hasan, Dzulkifli. (2012). Edinburgh Guides to Islamic Finance Series Shariah Governance in Islamic Banks. Proquest ebrary.

Hendriksen, E. S., dan M. Breda. (1992). Accounting Theory. 5th Edition. USA: Richard D Irwin Inc.

Hikmah, N dan D. Rahmayanti. (2011). Faktor-Faktor Yang Mempengaruhi Luas Pengungkapan Corporate Governance Dalam Laporan Tahunan Perusahaan Perbankan Yang Terdaftar di BEI. Simposium nasional akuntansi XIV

Hossain M dan Hammami. H. (2009) Voluntary Disclosure In the Annual Report of an Emerging Country: Evidence From Bangladesh. Asia Pacific Conference on International Accounting Issues. 1221. Hawai

Othman, R,. Thani A.M., Ghani ., E.K. (2009). Determinant of Islamic Social Reporting Among Top Shariah Aproved companies in Bursa Malaysia. Research Journal of International Studies, 4-20.

Owunsu-Ansah, S. (1998). The Impact of Corporate Atributes on the Extent of Mandatory Disclosure and Reporting by Listed Companies in Zimbabwe. The International Journal of Accounting vol. 33, no. 5, 605-631.
Raditya, A.N. (2012). Analisis faktor yang mempengaruhi tingkat pengungkapan Islamic Social Reporting pada perusahaan yang masuk dalam Daftar Efek syariah. Skripsi.Universitas Indonesia. Jakarta.

Sari, Reka Yufita (2018). Pengaruh Ukuran Perusahaan, Umur Perusahaan, Profitabilitas, Leverage Terhadap Pengungkapan Islamic Social Responsibility pada Bank Umum Syariah di Periode 2013-2017. Skripsi. IAIN Purwokerto. Purwokerto.

Sedyadi, G.S.M (2014) Kajian Pengaruh Desentralisasi Fiskal Asimetri di Indonesia terhadap Efisiensi Penyediaan Barang dan Layanan Publik Sektor Pendidikan. Tesis, Institut Teknologi Bandung. Bandung

Sharma, Narendra. (2014). Extent of Corporate Governance Disclosure by Banks and Financial Companies Listed on Nepal Stock Exchange. Advances in Accounting, Incorporating Advances in International Accounting..

Usanti, Trisandini dan Abdul Shomad. (2013). Transaksi Bank Syariah. Jakarta: PT. Bumi Aksara. 